\title{
Transatlantica
}

Revue d'études américaines. American Studies Journal

\section{Elisabeth Bouzonviller. F. S. Fitzgerald. Ecrivain du} déséquilibre.

Paris : Belin, 2000. 128 p. http://www.editions-belin.com

\section{Pascale Antolin}

\section{(2) OpenEdition}

\section{Journals}

Édition électronique

URL : http://journals.openedition.org/transatlantica/715

DOI : $10.4000 /$ transatlantica.715

ISSN : 1765-2766

Éditeur

AFEA

\section{Référence électronique}

Pascale Antolin, «Elisabeth Bouzonviller. F. S. Fitzgerald. Ecrivain du déséquilibre. », Transatlantica [En ligne], 1 | 2003, mis en ligne le 05 avril 2006, consulté le 29 avril 2021. URL : http://

journals.openedition.org/transatlantica/715; DOI : https://doi.org/10.4000/transatlantica.715

Ce document a été généré automatiquement le 29 avril 2021.

\section{c) (i) $(9)$}

Transatlantica - Revue d'études américaines est mis à disposition selon les termes de la licence Creative Commons Attribution - Pas d'Utilisation Commerciale - Pas de Modification 4.0 International. 


\section{Elisabeth Bouzonviller. F. S. Fitzgerald. Ecrivain du déséquilibre.}

Paris : Belin, 2000. 128 p. http://www.editions-belin.com

Pascale Antolin

1 La collection « Voix américaines » vient de s'attaquer à l'un des piliers de la littérature américaine : Francis Scott Fitzgerald. Cerner le géant fitzgeraldien en 128 pages n'est certes pas chose facile mais Elisabeth Bouzonviller relève le défi avec finesse et conviction. Pour ce faire, elle s'appuie sur les œuvres (les cinq romans et une quinzaine de nouvelles parmi les plus célèbres) mais aussi sur les textes personnels de l'écrivain (lettres, essais, carnets) qu'elle cite abondamment, si bien que le lecteur n'a qu'à se laisser convaincre.

2 Et la démarche est aussi logique que cohérente. D'un bout à l'autre, Elisabeth Bouzonviller poursuit la limite, explore la faille qui, selon elle, déchire l'univers fitzgeraldien jusqu'au cœur de l'être. Se fondant sur les théories psychanalytiques lacaniennes, elle nous mène ainsi du thématique à l'ontologique. Au point de départ, «la guerre des sexes ", consécutive à l'émancipation de la femme américaine et à l'arrivée sur la scène sociale de la "flapper", cette femme libérée qu'incarnent la plupart des héroïnes fitzgeraldiennes. En face d'elle, en effet, l'homme est désorienté, privé de ses repères autant que de ses rôles traditionnels. Les analyses d'Elisabeth Bouzonviller à ce propos s'appuient presque systématiquement sur l'onomastique dont elle tire, semble-t-il, le meilleur parti. Ce clivage initial au sein du couple la conduit ensuite à l'évocation d'une famille défaillante elle aussi puisque le père, dépassé, est incapable de faire la loi. Les enfants, du coup, n'ont plus la possiblilité de grandir, de mûrir, et le pays tout entier se change en " une vaste nursery ». On voit apparaître, dès lors, une société en crise, ravagée par la violence, menacée de sombrer dans le chaos. Et c'est ce point où tout bascule, cette limite précisément, que va chercher Elisabeth Bouzonviller dans une étude non seulement de la topographie (le passage qu'elle consacre aux «Frontières et [aux] promontoires" est fort bienvenu) mais aussi des ténèbres, pour ce que s'y « dessine la vérité de l'être ». Le point d'aboutissement de son 
analyse est le déséquilibre, consécutif à un manque-à-être fondamental que seule peut traquer ou plutôt « tracer » l'écriture.

3 Elisabeth Bouzonviller aurait peut-être pu accorder plus de place à l'écriture précisément, afin de démasquer ce manque, de donner à voir cette absence, ce blanc inscrit au cœur du texte, dans des jeux souvent ironiques de montrer-cacher. Mais l'ouvrage sort des sentiers battus et fournit une grille de lecture aussi personnelle que pertinente, un outil précieux tant pour les spécialistes que pour les amateurs de Fitzgerald.

INDEX

Thèmes : Recensions

\section{AUTEUR}

PASCALE ANTOLIN

Université Michel de Montaigne - Bordeaux 3 